\title{
PECULIARITIES OF THE HUMAN RESOURCES MANAGEMENT PROCESS IN SERVICE ORGANIZATIONS - RESEARCH RESULTS
}

\author{
Tijana Savić Tot ${ }^{1}$ \\ Vilmoš Tot $^{2}$ (i) \\ Marija Runić Ristić ${ }^{3}$ \\ Maja Aleksić ${ }^{4}$ (D)
}

DOI: https://doi.org/10.31410/tmt.2020.457

\begin{abstract}
Service organizations have, over the years, been constantly faced with increasing customer demand, growing competition, digitalization, and numerous changes in the business environment to which they must adapt in order to survive in the marketplace. As the main specificity of service organizations is reflected in the "intangibility" of their services, for customers who are participants in the service process and for employees who directly depend on the quality of service, service process and customer satisfaction, defining appropriate activities of Human Resources Management process, which manages employees, undoubtedly represents a priority that provides a competitive advantage. This paper will present the results of the research on the characteristics of eight selected sub-processes in the process of Human Resource Management in service versus production organizations of Rasina district, in order to define their specifics and point out their advantages and disadvantages.
\end{abstract}

Keywords: Human Resources Management Process, Service organizations, Rasina district.

\section{INTRODUCTION}

$\mathrm{B}_{\mathrm{p}}^{\mathrm{e}}$ eing faced with all the difficulties of everyday life that today brings, caused by the global pandemic which, in addition to all health, social, economic consequences, limited movement and restrictions on the number of people indoors has resulted in many changes that need to be managed. One of the service activities within the industry that is most endangered is tourism, whose current way of doing business and providing services will most certainly change significantly. Certainly, people employed in the tourism sector have the biggest problem, both because of the characteristics of the service they provide and because of the great uncertainty of the business environment. Today, unfortunately, we do not have an answer as to how long this situation will last and it is very difficult to predict what losses the service sector will go through during this period. Current data from the Statistical Office of the Republic of Serbia for October show that the number of tourists in our country compared to the same period last year decreased by $43.1 \%$ while the number of overnight stays decreased by $22.9 \%$. Also, the number of nights spent by foreign tourists decreased by $76.3 \%$. The National Association of Tourist Organizations in Serbia points to the fact that the turnover within this activity dropped by $90 \%$ while 100,000 employees directly or indirectly depend on this activity, which is a major economic and social problem. What is certain is that, after creating the conditions for the return to the market, human resources in the entire service sector and especially in tourism will enable the survival and continuation of the business.

Faculty of Management, Sremski Karlovci, Serbia

Faculty of Information Technology and Engineering, Belgrade, Serbia

Faculty of Management, Sremski Karlovci, Serbia

Phd. student, Faculty of Technical Sciences, Novi Sad, Serbia 
The function within the organization in charge of this work is Human Resource Management. The Human Resource Management process itself is defined by a set of sub-processes with their activities. This paper will focus on the characteristics that are specific for employees in the service sector, as opposed to employees in the manufacturing sector. These features can be a signpost that indicates the possibility of overcoming the problem or the causes of the problem.

On this basis, the initial hypothesis of the paper was formulated: There is a statistically significant difference in the attitudes of respondents related to Human Resource Management activities in the service sector versus respondents from the manufacturing sector.

\section{HUMAN RESOURCE MANAGEMENT}

As human labour was a subject of interest in ancient civilizations, the scientific field of Human Resource Management has developed in the broader context of social, industrial and economic development and is a response to the key changes that industrialization has had on society and work (Miller, FB, Coghill, MA, 1964). Human Resource Management is an area of organizational science that deals with the study of all aspects of employment in an organization (Dulebohn, J. H., Ferris, G. R., Stodd, J. T., 1995). The very name of the field of Human Resource Management had its development in the world and in our country, but it was primarily influenced by American literature in the early 1980s. The previous name of the area was Personnel or Personnel Management, whose role was administrative and advisory, with the primary goal of reducing labour costs and increasing productivity. The new term represented not only a change in the old name of a scientific field or management function, but also a change in business philosophy, from a focus on labour costs to a focus on understanding employees as a resource in achieving business results. This phase is characterized by detailed design and definition of Human Resource Management process activities, the growth of the importance of the function itself and its role in the organization and the understanding of the function as a means to achieve organizational strategy. The early 1990s were marked by numerous restructurings of organizations (downsizing, outsourcing, re-engineering, informatization, etc.), which initiated the development and another change in the role of Human Resource Management into Strategic Human Resource Management that sees employees as a source of competitive advantage and equal partners in realization of the organization's strategy.

As the basic role of the function of Human Resource Management is the development of processes and related activities in order to harmonize them with the strategy of the organization, most of the work in this paper is devoted to researching their impact on the performance of the organization.

Author West, M. et al. (1997) has been researching the types and impact of management activities on the performance of the company for five years, where he concluded that changes in profits are due to the application of different methods of selection, worker orientation, training, rewarding as well as business design and not strategic positions, investment in technology or quality.

In 1999, Watson Wyatt, creator of the Human Capital Index, in a study conducted in 400 organizations in the US and Canada identified 30 key activities in Human Resource Management that are associated with a $30 \%$ increase in the market value of the organization. Eleven years later, the same research resulted in the identification of the 43 activities, which W. Wyatt categorized into the 5 dimensions, given the impact in increasing the company's market value (reward- 
ing performance, collegial and flexible workplace, recruiting, communicating, training, career management). Ten years later, a similar survey was conducted in 16 European countries, which identified 19 basic activities that are associated with a 26\% increase in the market value of the company. Also, differences between European and American companies in Human Resource Management were identified, which initiated further research in the direction of comparative analysis between countries in which it was determined that the differences are primarily due to different cultures, norms, values, attitudes, as well as other characteristics of the workforce.

Research conducted in America (Gerhart, B., 2005) confirmed the correlation between employee's productivity and/or organizational performance with activities within the recruitment and selection sub-process (Koch, JM, McGrath, JM, 1996), employee education (Bartel, AP, 1994), impact assessments (McDonald, D., Smith, A., 1995), compensations and benefits (Gerhart, B., Trevor, CO, 1996; Gómez-Mejía, LR, 1992) and activities that support innovation (Delaney, JT , Huselid MA, 1996; Huselid, MA, 1995). Research has also shown that organizations that implement these sub-processes perform better than organizations that have not had formalized sub-processes within the same industry (Bartel, AP, 2004; Black, SE, Lynch, L., 2001, 2004; Ichiniowski, C., Shaw, K., Prennushi, G., 1997).

Based on the research, it can be concluded that the views, practices and processes of Human Resource Management differ in content, manner of performance and characteristics; however, the elements (sub-processes) and activities of the Human Resource Management process are performed in almost every organization regardless of its activity and size.

In the following parts of this paper, the focus will be on the detailed definition and explanation of selected sub-processes (elements) of $\mathrm{C}$ in the organization, as well as the definition of the activities of each sub-process.

\subsection{Human Resource Management Process}

The process of Human Resource Management in the organization implies certain elements or sub-processes which in turn imply different activities. The selection of appropriate sub-processes and their activities are conditioned by a large number of factors, primarily internal, which include: the role of activities related to the human resources management subsystem in the organization, organization and status of Human Resources Management, number and structure of engaged human resources experts, level of development of other subsystems in the organization, goals of human resources strategy, corporate goals, principles and policies of human resources, activities of the organization, its size, the impact of the environment on the Human Resources Management process, attitudes of management and governing bodies towards human resources' activities, management expertise and its relationship to changes, the content of the concept of organization development, etc. In other words, the process of Human Resource Management is different in each organization, its structure (by which we mean processes and activities) depends on the aforementioned factors that serve as a guide in defining and adapting the process itself.

Over the years, various authors have defined the necessary elements of the Human Resource Management process that increase the performance of the organization (Torrington, D., (2004), Vujić, V., and Ćamilović, S., (2007)) with differences that are conditioned in the way their observations, i.e., whether they view the function of human resources management as strategic or as an operational one. Within this paper, those elements or sub-processes were singled out, which, according 
to the group of authors Noe, R., Hollenbeck, J., Gerhart, B., Wright, P. M., (2005), confirmed their influence on the performance of the organization. Thus, the management of the Human Resource Management process can be implemented by defining the following elements and their activities:

1. Job analysis - the process of collecting relevant information about jobs and defining the knowledge, skills and abilities needed to perform a particular job,

2. Human resource planning - a process in which, based on anticipated changes in the internal and external environment, human resource needs are predicted,

3. Recruitment of human resources - the process of attracting qualified candidates in such a number which will allow the organization to choose the best ones to fill vacancies,

4. Selection of human resources - a process in which a choice is made between the registered candidates for a particular job and a decision is made on employment, i.e., rejection of candidates,

5. Motivation and job satisfaction - the process of defining motivational factors, incentives and strategies that are built into the organizational environment in order to motivate employees, as well as defining factors that affect job satisfaction or dissatisfaction

6. Human resources development and training - the development process is aimed at creating learning opportunities to help employees in their personal development and prepare for future job and career development requirements, while the training process is focused on changes in specific knowledge and skills, attitudes and / or behaviour aimed at improving the performance of employees in their workplace,

7. Performance management and rewarding employees - a process in which the individual contribution of employees in achieving organizational goals in a defined period is assessed.

Within this paper, the Human Resource Management process is observed by examining the following elements: job analysis, human resource planning, human resource recruitment, human resource selection, development and education, job introduction and orientation, motivation and job satisfaction and performance appraisal and reward. Within each individual element, the necessary activities and their role will be briefly described in order to better understand their contribution to more efficient performance and competitive advantage.

\subsubsection{Job Analysis}

Although research related to job analysis is rare, we can still divide it into two basic groups (Siddique, M. C., 2004). The first group includes previous research focused on the content of job analysis, its role and connection with other activities in the process of Human Resource Management that resulted in the development of techniques, procedures and methods necessary for its quality implementation (McCormic, E., 1979; Cornelius, E., 1979; Ash, R., 1988) and another group to which recent research focuses on - the strategic role of job analysis as a Human Resource Management activity that contributes to increasing organizational performance (Cascio, FW, 1998; Bowin, RB, Harvey, D., 2001). Over the years, under the influence of numerous changes in the environment and the acceptance of empirical results that testify to the contribution of job analysis in increasing the performance of the organization, a foundation was created to study its impact on achieving competitive advantage of the organization (Anthony, WP, 2002; Dessler, G., 2002). The importance of job analysis primarily stems from the fact that many theorists and practitioners in the field of Human Resource Management view it as the basis for the realization of most activities in the process of Human Resource Management (Schuler, RS, Jackson, SE, 1996; Sherman, A., et al. 1998). Dessler, G., 1999). Thus, job analysis is a 
basic prerequisite for quality planning, recruitment and selection of workers in the organization. Job analysis, as a basic prerequisite for the successful planning, includes the development of a detailed description of the tasks involved in the job, establishing relationships and relations that the job has with other jobs and determining the knowledge, skills and abilities that employees must have in order to successfully perform the job. The results of the job analysis are job descriptions and job specifications. A job description is a written statement about what a job holder does, how and why he/she does it. It should accurately outline the content of work, environment and employment conditions. Based on the analysis of work, the organization forms criteria for recruiting and selecting workers, and the quality of human resources that they will hire depends on its quality. In essence, the business analysis should be a continuous activity in organizations that is adjusted to all the changes in the environment, customer requirements, technology, etc. There are numerous methods for job analysis. Some of them are job-oriented and some are worker-oriented, but in each case, each method has its own disadvantages and advantages. From previous practice, it can be concluded that several methods can be used together in order to obtain the most valid and complete picture of work obligations, responsibilities and behaviour.

\subsubsection{Human Resources Planning}

Human resource planning as an element of the Human Resource Management process is also the most complex set of activities in the organization which, in addition to the basic tasks of analysing and predicting the need and supply of human resources, harmonizing needs and supply and defining plans are a strategic framework for decision making. In order for strategies to be successful, the organization must have the right number of people with the appropriate skills, knowledge and abilities to implement them (Bahtijarević Šiber, F., 1999). Approaches to human resource planning have also evolved over the years under the influence of various changes. Human resource planning was viewed as an adjunct to organizational strategy, as a completely separate planning process, and ultimately as an integrated strategic process in the organization (Smith, J. B., Boroski, W. J., Davis, E. G., 2006). Author Bramham, J., (1989) in his first book "Human resource planning" highlights the difference between the two approaches in human resource planning. Namely, he made a difference between workforce planning as a quantitative approach and human resources planning in organizations which, in addition to the quantitative approach, includes numerous planning and development activities such as motivation, employee attitudes, organizational culture, etc. In contrast, other authors (Bennison, M., Casson, J., 1984; Thomason, G., 1988) reject these differences, considering that workforce planning is part of human resource planning. It is obvious that workforce planning is defined as an activity aimed at determining the difference between the required and available number of workers, while human resource planning is defined as a process that should be harmonized or with which strategic decisions in the organization should be harmonized. Author Armstrong, M., (2008) views this difference as a hard and soft approach in human resource planning. Human resource planning, he believes, focuses on both quantitative (how many employees are needed) and quality (what employee characteristics are needed) approach.

From all the above mentioned, it can be concluded that despite the constant changes that increase the uncertainty of the planning process in today's business environment, it still represents the basis of good business, its control, decision-making framework and gaining a competitive advantage, but unlike the previous period in organizations that there is now an awareness of constantly adapting plans to changes in the environment. The period of adjustment of defined plans to current changes will depend on the industry in which the organization operates, their 
activities and more. As the process of human resources planning in the organization is strategic, its impact on business and gaining the competitive advantage of the organization is more than significant. As it was already mentioned, there are different approaches in human resource planning, but the most commonly used process in organizations involves the following elements (Noah, R., Hollenbeck, J., Gerhart, B., Wright, P. M., 2005):

1. analysis of the environment (external: labour market, legislation, culture of society, economy; internal: management, size of the organization, stages of development of the organization, organizational culture),

2. forecasting human resource needs,

3. forecasting the market offer of human resources,

4. harmonization of needs and supply,

5. defining action plans and evaluations.

\subsubsection{Recruitment of Human Resources}

Recruitment of human resources is one of the activities in which organizations have direct contact with the environment. What it means and who decides who is the right candidate, whether there is a system in the organization to assess the need for recruitment, which recruitment activities can improve or damage the image of the organization, what are the costs of recruitment and how we can manage them, are just some of the issues organizations are facing. The importance of answering the questions is seen in the growing number of studies over the years focused on studying the impact of elements of this process on the organization (Billsberry, J., 2007; Breaugh, J. A., Macan, T. H., Grambow, D. M., 2008).

According to the author Bahtijarević Šiber, F., (1999), recruitment is defined as ,the process of attracting candidates for vacancies, who have the necessary abilities, skills and characteristics to successfully perform jobs and achieve goals." The process itself includes a series of activities and procedures that determine the characteristics of the candidates who apply to job vacancies, and these activities are later applied in the selection process. One of the same author's definitions, which explains the recruitment process as ,the process of aligning the professional preferences and goals of individuals with the goals of the organization", best describes the modern approach to Human Resource Management that views employees as an inexhaustible renewable resource for which, if we want maximum results, we need to create conditions that will be able to meet their needs, expectations and ambitions.

According to the authors Noah, R., Hollenbeck, J., Gerhart, B., Wright P. M., (2005) human resource recruitment is also defined as a practice or activity that an organization carries out in order to identify and attract potential candidates.

Human Resource Management experts define the recruitment process in similar ways and fully agree with the fact that the purpose of the recruitment process itself is to attract enough quality candidates to be able to choose the best ones.

Therefore, based on the above mentioned, it can be concluded that recruitment is a process of gathering candidates with certain qualifications, skills, abilities and knowledge that will achieve organizational goals by performing jobs. A recruited set is a set of candidates from which the one that best meets the requirements of the job is selected and which must have three characteristics: 
1. large enough to have a sufficient number of quality candidates,

2. small enough to be managed well (you don't want to have several hundred candidates for a particular job), and

3. quality oriented.

The process of human resources recruitment, according to the author Dessler, G., (2002) implies the following elements:

1. identification of the target labour market (place of recruitment),

2. selection of recruitment sources, and

3. control and evaluation of the recruitment process.

So, in order to have quality workers at all, you have to find them first. Employers today are aware of the fact that the success of the organization depends on the quality of human resources at their disposal, moreover, in many sectors of the labour market there is a real war for the best people. With quality and efficient recruitment and selection, you can reach professionals who will be able to successfully perform the jobs required by certain positions, who will have appropriate development conditions and who will be satisfied in the workplace. The great contribution of the process of recruitment and selection of human resources in improving the performance of the organization has been confirmed by many empirical studies (Patterson, M., West, M., Lawtthorn, R., Nickell, S., 1997).

Recruitment and selection processes are aimed at identifying, attracting and selecting suitable candidates who will meet organizational expectations. Recruitment and selection are inseparable processes "where recruitment stops selection begins" (Anderson, C., 1994). Regardless of their inseparability, it is important to distinguish between these two activities.

\subsubsection{Human resource selection}

The author Bogićević Milkić, B., (2006) defines the selection process as a set of activities that select between available candidates for a particular job and make a decision on their employment or rejection, while the author Bahtijarević Šiber, F., (1999) defines selection as a procedure by which by applying pre-established and standardized methods and techniques for a particular job, and those who best meet its requirements and become selected. Although there do not seem to be significant differences in defining the concept of selection between different authors, we can see that the author Bahtijarević Šiber, F., (1999) by defining the selection process, emphasizes the importance of job analysis on which the criteria for methods and techniques that are unique to each organization are defined. He also emphasizes that the goal of the selection process is to forecast the maximum future of both work and organizational success, which indisputably emphasizes the importance of the role of each individual in achieving organizational goals. It is up to the organizations to select candidates with a systematized approach who will contribute to the achievement of organizational goals through their work. The core of quality selection means achieving maximum compliance between job requirements and individual characteristics, i.e., identifying those candidates who, with their characteristics and potentials, fully meet the requirements of the job (Bahtijarević Šiber F., 1999).

The first step in the selection process is to define the selection criteria and the specification of the candidates. If the criteria by which candidates are categorized are not clear, it is impossible to reach reliable decisions when designing an appropriate selection process. Selection criteria 
are usually presented in the form of specifications, i.e., a description of the person representing the ideal candidate. Lewis, C., (1985) singles out three selection criteria:

a) organizational criteria - are those characteristics of workers that the organization values,

b) functional (departmental criteria) - which include e.g. defining the appropriate interpersonal skills of all members of the human resources department, or the marketing, research and development department, etc.

c) individual job criteria - are contained in the job description and specification and the description of the person performed based on job analysis.

Based on the above criteria, it can be concluded that for their definition, the cooperation of a team of experts (a member of the human resources sector, a member of the sector looking for an employee, a member of top management, and a psychologist) is necessary.

The second step in the selection process is choosing the selection methods. The purpose of selecting appropriate methods is to collect information whose analyses are used to predict the work success of an individual and to determine the degree of compliance between job requirements and individual characteristics of potential candidates (Torrington, D., Hall, L., Taylor, S., 2004).

What methods will be used depends on the job, i.e., the position for which we select candidates, general employment policies and strategies, the expertise of people dealing with human resources, philosophies and attitudes of management, etc. In essence, the information gathered and the methods chosen are the basis for deciding on the candidate selection process.

The third and final step in the selection process is to decide on the selection of candidates. Decision-making involves evaluating each candidate according to the selection criteria defined in the person's specification, and not comparing one candidate with another. Also, making the final decision represents a critical stage in the selection process, given that a choice must be made between several candidates applying for a given job. What is important for the decision on the election is what the candidate can do and what the candidate wants, given that these two factors directly affect the candidate's performance.

\subsubsection{Induction and Orientation}

Induction (introduction to work) and orientation, as an element of the Human Resource Management process, if it exists in organizations, is most often neglected (Brown, S. P., 1996). However, as numerous studies (DeCenzo, AD, Robbins, PS, Verhulst, LS, 2010) have shown over the years, the process of induction and orientation of workers is the right mechanism primarily set to reduce initial costs of possible mistakes that new employees make, to reduce anxiety and setting a framework of desirable behaviour, to reduce employee turnover due to feelings of inferiority, to make superiors spend less time in explaining work to new employees, to develop realistic job expectations, increase job satisfaction, etc., and nowadays more and more time and resources are invested in organizations into its design. According to a study by the Salvesten Stetson Group (Amble, B., 2006), about two-thirds of U.S. organizations believe that improving orientation programs is necessary in order to improve motivation, job satisfaction, and employee retention, or to enhance and retain the human capital that is the basis for gaining competitive advantage. 
According to the authors Klein, H. J., and Weaver, N. A., (2000) the process of employee orientation is viewed as an integral part of training designed to introduce new employees to their new roles and responsibilities, to colleagues and the organization as a whole. Well-designed orientation programs result, the authors believe, in higher productivity, loyalty, and employee contribution. According to French, J. R. P., (1994) orientation is the process of introducing new employees to organization and work. Authors Werner, M., and Randy, L. D., (2009) view the orientation process as part of socialization. Authors Gregg, P., and Wadsworth, J., (1999) in their analyses show that out of 870,000 workers who started a new job in $1992,17 \%$ of them left the job in three months and $42 \%$ in twelve months, as a result of poor adjustment of expectations with the job itself and inefficient introduction to the job.

According to the authors Torrington, D., Hall, L., Taylor, S., (2004) the introduction of new workers into work has several goals and all are aimed at preparing these new workers for more efficient work in new jobs in the shortest possible time. New employees must learn in the shortest possible time what is expected of them, what they can expect from other employees, as well as the adoption of values, culture and norms of behaviour in the organization.

As orientation and introduction to work are important for new workers, they are equally important for existing workers who have been transferred to another job. Although there is no universal orientation process, most are aimed at getting to know the job, organization, department, procedures and rules, organizational culture and employee development, in order to improve employee performance and prevent the outflow of human capital (Ganser, T., 2000).

According to authors Mondy, R. W., et al. (2002) the basic elements of the orientation process are:

a) Situation related to employment - implies acquaintance with basic information about the job and its role in achieving the goals of the department and organization,

b) Procedures and rules - means getting acquainted with the basic procedures and rules that are, in most organizations, written in the manual for employees,

c) Compensation and benefits - means getting acquainted with the reward system in the organization,

d) Organizational culture - means fitting into the system of values, beliefs and norms of behaviour characteristic of a particular organization,

e) Teamwork - means emphasizing the importance of teamwork between employees within the department but with employees in other departments in order to understand or experience the organization as a whole,

f) Employee development - means getting acquainted with the need for continuous improvement of knowledge, skills and abilities of employees in the role of the organization in supporting employees in achieving development goals,

g) Socialization - means the process in which the newly employed worker adjusts and adapts to the working environment and business rules of the entire organization.

\subsubsection{Motivation and Job Satisfaction}

Motivation and job satisfaction as two factors that have a significant impact on the efficiency and effectiveness of the organization have been topics of study and research for years. It is important to point out that motivation and job satisfaction are two different factors and as such contribute to different influences on employee behaviour. According to the author Carr, G., (2005) motivation is the result of expectations in the future while job satisfaction is the result of past events. In the 
context of organization, motivation can be viewed from two aspects (Bahtijarević Šiber, F., 1999). From the aspect of an individual, motivation is an internal state that leads to the achievement of a goal. From the manager's point of view, motivation is an activity that ensures that people strive for set goals and achieve them. Both aspects have a common meaning and the investment of efforts to achieve goals, i.e., it is seen as a process of initiating and directing efforts and activities in order to achieve individual and organizational goals. According to the author Bahtijarević Šiber, F., (1999), the system of motivation is comprised of the comprehensiveness of motivational factors, incentive measures and motivation strategies that are consciously or unconsciously incorporated into the organizational environment in order to motivate employees. A quality system, according to the author, must provide four types of behaviour: attracting and retaining the best people, quality execution of tasks and realization of set goals, encouraging creativity, solving current and development problems, creating new products/services, and identification of employees with the organization. The motivation system in the organization must be comprehensive and, in addition to the above, take into account the individual needs and aspirations of each individual employee, by creating numerous mechanisms to meet them and encourage various forms of behaviour that affect the success of the organization. The basic step in creating a system of motivation is certainly the goals that the organization strives to achieve with the basic rule of rewarding of what we want to achieve and what we want to be more of (Bahtijarevic Shiber, F., 1999). Motivation strategies such as material stimulation, redesign and enrichment of work, management style, employee participation, goal management, flexible working hours, organizational culture, recognition and praise, training and career development aim to increase motivational potential on the both individual and functional level, as well as in the organization as a whole.

Job satisfaction, according to the author Bloisi, W., (2003), refers to the attitude and level of satisfaction in all aspects of work. Respectively, according to the authors Devadoss, P., and Pan, S., (2007), job satisfaction is an individual's attitude based on his or her subjective assessment and feelings towards the level of satisfaction with job-related factors. The author Locke, E. A., (1976) views job satisfaction as a positive feeling after a job is done, that has met an individual's expectations. According to the author Armstrong, M., (2008) job satisfaction is primarily influenced by intrinsic and extrinsic factors of motivation, quality of supervision/control of work, social factors and the degree of success/failure in work. Authors Purcell, J., et al., (2003) in their research of job satisfaction factors singled out the possibility of advancement, the importance of work, teamwork and job challenge as factors of significant influence. Job satisfaction according to the author Mullins, JL, (2005) is influenced by numerous factors: Individual factors (personality, education, abilities) Social factors (relationships with colleagues, group norms), Cultural factors (basic attitudes, beliefs and values), Organizational factors (structure, policy, nature of work, leadership) and environmental factors (economic, social, government influence). Each of these factors can affect the individual and his job satisfaction, i.e., the individual may be satisfied with one and dissatisfied with another factor. In order to determine which aspects of the job an individual is satisfied or dissatisfied with, structured questionnaires, interviews, a combination of questionnaires and interviews and a focus group are used.

Job satisfaction research has involved a large and complex survey of a large number of employees across the United States (Grubić Nešić, L., 2005). According to the structured sample, 15,000 employees of all levels of management structures were surveyed, of which 91\% were employed full-time, with an average age of about 33, and both sexes were proportionally represented. According to the results of the research, six factors have been identified that have a decisive influence on job satisfaction, namely: 
- Opportunities provided by the job (participation in interesting projects, a challenge that is not a "simple promotion", or a healthy need for an individual to be realized in the work he does),

- Stress (when stress is continuous, job satisfaction decreases),

- Leadership (employees are more satisfied if their managers do a good job, which means that they know how to motivate employees and that there is mutual trust),

- Labour standard (employees are more satisfied with their work if the relations in the working group are better and if mutual success is valued as significant),

- Appropriate and fair relationship (represents the knowledge that there is greater employee satisfaction, but also their performance if they are confident in the relationships that govern the organization), and

- Use of adequate authority (implies relations between employees related to decision-making, participation in decision-making relevant to the business and insight into the results of such decisions).

\subsubsection{Performance Assessment and Rewarding}

Research on performance appraisal and employee rewards began in the 1920s and continues to this day (DeNisi, A., 2008). According to the authors Foot, M., and Hook, C., (2011) the ultimate goal of performance management is to motivate employees to achieve organizational goals. Author DeNisi, A., (2000) views Performance Management as a set of activities by which an organization seeks to increase the performance of individuals and groups with the ultimate goal of increasing the performance of the organization as a whole. Similarly, authors Armstrong, M., and Baron, A., (1998) define Performance Management as a process that focuses on increasing an organization's performance by improving performance and developing the capabilities of individuals and teams, thus emphasizing the strategic and integrated role of the process itself. Performance Management can be defined as a complex process of improving the performance of an organization by developing the performance of individuals and teams (Armstrong, M., 2008). In other words, performance management is an instrument for understanding and managing performance based on an agreed framework of planned goals, standards, and required competencies (Armstrong M., 2008). The main purpose of defining a performance management process is to build a common understanding of goals and develop human resources in such a way that will increase the likelihood that those goals will be achieved.

Authors studying the elements of the performance management process differ in the way of observation as well as the number of sub-processes that are necessary for efficient management (Aguinis, H., 2007, Pulakos, D. E., 2009).

In the following text of this paper, the process of performance management will be explained, according to the classification of the authors Foot, M., and Hook, C., (2011), by the following elements:

1. Statement of mission and vision - The statement of vision determines the direction; the mission defines future goals and ways of their realization, while values define beliefs. If employees at all levels in the organization do not understand the vision, mission and values as well as how their specific job contributes to their realization according to the author Naisby, A., (2002) performance management system will not achieve the expected results. 
2. Competence analysis - Competencies include the knowledge, skills and abilities that are necessary for an individual to be able to perform a particular job. They are also used as performance measurement standards.

3. Performance rewarding - performance rewarding is defined as feedback on the achieved performance because it shows the commitment of top management and managers to employees, increases morale and strengthens two-way communication and connects organizational with individual goals.

4. Defining performance goals and standards - A successful performance appraisal system is based on an organization's ability to measure and develop employee's performance by setting appropriate goals and standards (Naisby, A., 2002).

5. Assessment of personal development - implies regular checking of the achieved performance of employees as well as providing feedback on the current performance. The frequency of assessments will depend on the needs of the organization but should not be performed less than four times a year (Naisby, A., 2002).

6. Impact assessment - is the process of providing feedback on the achieved performance, setting future goals and plans for their implementation. According to the author Naisby, A., (2002) performance assessment shows the commitment of top management and middle management to employees, increases morale and strengthens two-way communication and also connects the individual with organizational goals.

7. 360-degree evaluation - Ward, P. T., (1994) defined a 360-degree feedback approach as a systematic collection of information about the performance of individuals and teams by all stakeholders involved in business processes.

8. Cultural aspect - implies harmonization with the culture of the country in which the system is developing. (Mendonca, M., \& Kanungo, N.R., 1996).

\subsubsection{Human Resources Development and Education}

Today, the concept of continuing education in the workplace is becoming one of the most important elements of Human Resource Management and development in an organization. Employee development is a continuous process that includes formal education, work experience, relationships with other people and assessment of personality and abilities, which allows the employee to prepare for future jobs (Bogićević Milkić, B., 2006). As training and education are given increasing strategic importance, it is very difficult to draw a clear line between training and employee development. While employee development is focused on adapting to future job needs, training is focused on adapting to current job needs (Jackson, S. E., \& Schuler, R. S., 1995).

For a long time, employee training and education, as well as the function of Human Resource Management, have been viewed as a cost rather than an investment, while reduction of the workforce remains one of the main cost reduction strategies (Uchitelle, L., Kleinfield, N., 1996). The most comprehensive study on the impact of training and education of employees on business results is certainly the study by Hansson, B., (2001), where he conducted research in 6000 organizations in 26 different European countries and proved their positive impact on reducing turnover, increasing performance, profit and stock price increase. Another important study on the impact of training and education on the organization's business is a study conducted in the UK (Tamkin, P., et al., 2004) in which it was proven that investing in employee education by profit funds exceeds the cost per worker, and it was also proven that more efficient organizations employ more educated workers and that different types of training affect the improvement of different results. Many studies over the years have shown that practices in Human Resource Management and 
development significantly affect organizational outcomes (Miles, RE, Snow, CC, 1984; Schuler, RS, Jackson, SE, 1987; Lengnick-Hall, Lengnick-Hall, 1990; Baird, L., Meshoulam, I., 1988; Schuler, RS, Jackson, SE, Rivero, JCR, 1989; Wright, PM, Snell, SA, 1998; Jackson, SE, Schuler, RS, 1995; Wright, PM, Smart, DL, McMahan, GC, 1995; Delery, JE, 1998; Barney, JB, Wright, PM, 1998; Kepes, S., Delery JE, 2007; Shih, HA, Chiang, YH, Hsu, CC 2006), but the problem of adapting these practices to the conditions in which the company operates and the characteristics of the workforce at its disposal remains unsolved.

For an average employee, additional training means improving skills, job satisfaction and increasing their own value in the labour market. For organizations, the best response to future challenges is highly trained and motivated workers. One of the ways in which the human resources department can contribute to the creation of competitive advantage is by defining employee training and education programs in order to create intellectual capital (Noah, R., et al., 2000).

The concept of development of education of both individuals, as members of society, and employees, as members of the organization, becomes one of the key factors for gaining a competitive advantage in today's knowledge economy and a condition for the survival of organizations (Swanson, A. R., Holton, E. F., 2001). The development of human resources in the organization, education and training in the workplace, is one of the ways to achieve this goal. All these data lead to the conclusion that organizations are becoming the most important educational institutions today.

All of the above leads us to the need for systematic monitoring and improvement of knowledge at the organizational level, and the following model of the process of human resources development in organizations can help us, which contains the following elements (Bahtijarević - Šiber, F., 1999):

1. Determining the educational needs of the organization - the main task of this phase is to determine what knowledge, skills and abilities employees should have to successfully perform tasks and achieve organizational goals, which employees do not have knowledge of or do have insufficient knowledge and skills and whether education will address these shortcomings. In order to answer these questions, it is necessary to conduct detailed analyses on three levels: analysis of the organization, analysis of the work and analysis of the executor of the work, i.e., an individual.

a. the analysis of the organization provides a general framework, direction and needs for education. It is aimed at identifying educational needs from the perspective of the organization, its goals, business strategy, organizational units, culture, change, resources and educational opportunities.

b. job analysis can be defined as "the process of gathering relevant job information and specifying the knowledge, abilities, skills, and other requirements necessary to perform a particular job" (Schuler, R. S., 1995).

c. the analysis of the individual provides an answer to the question of who needs education, as well as what knowledge should be the subject of training. The basis for determining individual educational needs is the analysis of the harmonization of necessary and available knowledge, skills and abilities to perform a certain job. The education of individuals is necessary when it comes to changing work requirements, changing technology, changing standards, etc.

2. Determining the goals of education - Goals are the starting point for the design of educational programs but also the basis for determining the criteria for assessing their success.

3. Determining the content and programs of education - the contents and programs of education are related to the needs and goals that arise from them. There are several lev- 
els and types of educational needs in organizations that determine the specific contents of individual educational programs. The first level of needs is aimed at training employees for current jobs and eliminating the gap between expected and actual success that usually arises as a result of the discrepancy between the job requirements and the educational profile of the executor. The second level of educational needs is related to the expansion of knowledge of individuals and thus increase the ability to perform more complex and diverse tasks within the same organizational level. The third level of organizational needs is related to individual career development, realization of succession plans, etc., i.e., preparation of employees for performing more complex and demanding jobs. The fourth level of educational needs is related to the future. It includes education and training programs based on a predicted picture of the knowledge and skills needed to achieve a particular strategy. Each level of educational needs sets different requirements in terms of educational programs and content.

While the levels of educational needs indicate the intensity and depth of the required education, the types of educational needs indicate its content, i.e., which skills and knowledge should be focused on. Based on Katz's categorization of skills and knowledge within the organization, we can categorize four types of educational needs (Katz, R. L., 1974):

1. basic knowledge and skills,

2. technical, professional skills,

3. interpersonal skills, and

4. conceptual, strategic skills.

4. Selection of methods and techniques of education - Different methods are linked to specific goals and programs of training and education. In general, all methods can be divided into two groups, i.e., on-the-job education methods and off-the-job education methods. The choice of the appropriate method depends on the educational program and its goals. The key question is what should be learnt.

5. Evaluation of educational programs - represents the final phase in the process of education and development of educational programs in which it is examined to what extent the set educational goals have been achieved and realized. The evaluation of educational programs in principle has two purposes: to determine whether the program has achieved its goals and whether there has been a transfer of the learnt to work, or change of work behaviour and success, and to determine the quality of organization, the content and implementation of programs for further improvement.

\section{THE RESEARCH}

The problem of this paper in the empirical part is to determine the differences in the application of Human Resource Management process activities represented in service and production organizations. The goals of the theoretical part of the paper were to analyse the content of contemporary literature in the field of Human Resource Management and defining the activities of the human resources management process, while the empirical goals of the paper were aimed at determining differences between organizations of different activities (service and production).

As it is defined in the introductory part, the initial hypothesis of the paper is:

H: There is a statistically significant difference in the attitudes of respondents related to human resource management activities in the service sector versus respondents from the manufacturing sector. 
The questionnaire, which was conceived for one larger research volume (Savić Tot, T., doctoral dissertation 2016), examined managers employed at all three management levels of economic entities in the Rasina district. The research instrument is conceived in the batteries of issues related to human resources management activities in the following sub-processes:

- job analysis,

- human resource planning,

- recruitment of human resources,

- selection of human resources,

- introduction to work and orientation,

- motivation and job satisfaction,

- performance appraisal and rewarding employees, and

- human resource development.

The questionnaire used a five-point Likert scale in which the respondents, by circling one of the offered alternatives, state the degree of agreement or disagreement with what is the content of the question for the following values:

1 - I don't agree at all,

2 - I partially disagree,

3 - I don't know,

4 - I partially agree, and

5 - I completely agree,

as well as closed-ended questions in which the respondents had the opportunity to complete one or more offered answers, as well as an alternative to writing additional answers if it was not provided by the questionnaire.

The Alpha coefficient was applied for the reliability of the Questionnaire. Considering that the reliability of the Alpha coefficient ranges from 0 to 1 , based on the obtained result, it can be concluded that the reliability of the Questionnaire is high.

In the realization of the research, the following statistical methods were applied:

a) Mann-Whitney test - Mann-Whitney U-test is equivalent to the parametric t-test, because it compares two groups of data, but over the median.

b) Spearman's correlation rank - Spearman's correlation coefficient (product of correlation rank) is used to measure the relationship between variables in cases where it is not possible to apply Pearson's correlation coefficient. It is based on measuring the consistency of the relationship between variables, and the form of the relationship (e.g. the linear form which is a prerequisite for using the Pearson coefficient) is not important.

c) Pearson's chi-square test - The most common non-parametric estimate used is the $\chi^{2}$ test. $\chi^{2}$ distribution is used in scientific research when it should be determined whether a distribution of the obtained measurement results deviates significantly from another distribution or if they match.

The research sample consisted of 127 respondents, members of the management of the first, second (functional) and third (top) management level from 86 economic entities of Rasina district. The selection of organizations was made based on business success and geographical affiliation of the Rasina district in which the research was conducted. 
Table 1. Sample structure in relation to the activity of the organization

\begin{tabular}{|l|c|c|}
\hline Field: & No. of respondents & $\%$ \\
\hline Production & 58 & $46,03 \%$ \\
\hline Service & 68 & $53,97 \%$ \\
\hline Total & 126 & $100 \%$ \\
\hline
\end{tabular}

\subsection{The Results of the Research}

The following results were obtained by analysing the representation of the activities of the sub-process of job analysis in relation to the activities of the organization:

a) In relation to the activities of the organization, Mann -Whitney test found that respondents employed in service organizations with a higher score and degree of agreement rated the following activities unlike the respondents employed in production:

- You had the opportunity to discuss a description of your job with your superiors $(\mathrm{U}=1618.00, \mathrm{z}=-1.993, \mathrm{p}<0.05)$,

- Job descriptions clearly specify education and qualifications needed ( $U=1637.000$, $\mathrm{z}=-2.190, \mathrm{p}<0.05)$.

For other items, the Mann-Whitney test did not indicate significant differences.

Table 2. Testing the differences between respondents employed in production and service organizations in relation to the representation of the activities of the job analysis process using the Mann-Whitney test

\begin{tabular}{|c|c|c|c|}
\hline & \multicolumn{3}{|c|}{ Mann-Whitney } \\
\hline & $\mathrm{U}$ & $\mathrm{Z}$ & $\mathrm{p}$ \\
\hline $\begin{array}{l}\text { You had the opportunity to discuss a description of your job with } \\
\text { your superiors }\end{array}$ & 1618.000 & -1.993 & $.046^{*}$ \\
\hline $\begin{array}{l}\text { Job descriptions clearly specify education and qualifications } \\
\text { needed }\end{array}$ & 1637.000 & -2.190 & $.029 *$ \\
\hline
\end{tabular}

Meaning:

* $\quad$ Significance at a level less than 0,05

** Significance at a level less than 0,01

Pearson's $\chi^{2}$ test determined the differences between the respondents employed in organizations with different activities in the answer who does the systematization of jobs $(\chi 2=.900$, $\mathrm{p}=0.638$ ). In service organizations, the systematization of jobs was done by the human resources department, while in production organizations the systematization was done by the legal department of the organization.

The analysis of the representation of the activities of the human resources management planning sub-process in relation to the activities of the organization brought the following results:

a) In relation to the activity of the organization, the Mann-Whitney test established that the respondents employed in service organizations rated the following activities with a higher grade and degree of agreement than the respondents employed in production organizations:

- In your organization there is a continuous monitoring of retirement of employees for a period of 5 years $(U=1451.50, z=-2.825, p<0.01)$,

- In your organization there is a systematization of jobs $(U=1699.50, z=-2.110, p<0.05)$. 
Table 3. Testing the differences between respondents employed in production and service organizations in the representation of human resource planning process activities using the Mann-Whitney test

\begin{tabular}{|l|c|c|c|}
\cline { 2 - 3 } \multicolumn{1}{c|}{} & \multicolumn{3}{c|}{ Mann-Whitney } \\
\cline { 2 - 4 } \multicolumn{1}{c|}{} & $\mathrm{U}$ & $\mathrm{Z}$ & $\mathrm{p}$ \\
\hline $\begin{array}{l}\text { In your organization, there is a continuous monitoring of } \\
\text { employee retirement for a period of 5 years }\end{array}$ & 1451.500 & -2.825 & $.005^{* *}$ \\
\hline There is a systematization of jobs in your organization & 1699.500 & -2.110 & $.035^{*}$ \\
\hline
\end{tabular}

Grouping variable:type of activity

Meaning:

* $\quad$ Significance at a level less than 0,05

** Significance at a level less than 0,01

By analysing the representation of the activities of the recruitment sub-process in relation to the activities of the organization - the following results were obtained:

a) In relation to the activities of the organization Mann-Whitney test found that respondents employed in service organizations with a higher score and degree of agreement rated the following activities than respondents employed in production organizations:

- When the need arises for a new job, you hire potential candidates by selecting people from outside the organization $(\mathrm{U}=1106.00, \mathrm{z}=-2.418, \mathrm{p}<0.05)$,

- If the registered candidates do not meet the requirements of the competition, your organization informs them that they have been rejected $(U=1504.500, z=-2.192, p<0.05)$.

For other activities, the Mann-Whitney test did not indicate significant differences.

Table 4. Testing the differences between respondents employed in production and service organizations in relation to the represented activities of the process of recruiting human resourc-

es using the Mann-Whitney test

\begin{tabular}{|l|c|c|c|}
\cline { 2 - 4 } \multicolumn{1}{c|}{} & \multicolumn{3}{c|}{ Mann-Whitney } \\
\cline { 2 - 4 } \multicolumn{1}{c|}{$\begin{array}{l}\text { When the need arises for a new job, you hire potential candidates } \\
\text { by selecting people from outside the organization }\end{array}$} & 1106.000 & -2.418 & $.016^{*}$ \\
\hline $\begin{array}{l}\text { If the registered candidates do not meet the requirements of the } \\
\text { competition, your organization informs them that they have been } \\
\text { rejected }\end{array}$ & 1504.500 & -2.192 & $.028^{*}$ \\
\hline
\end{tabular}

Grouping variable:type of activity

Meaning:

* $\quad$ Significance at a level less than 0,05

** Significance at a level less than 0,01

The following results were obtained by analysing the representation of the activities of the selection sub-process in relation to the activities of the organization:

a) In relation to the activities of the organization Mann-Whitney test found that respondents employed in service organizations with a higher score and degree of agreement rated the following activities differently from respondents employed in production:

- Your organization uses knowledge tests to select employees ( $U=1662.50, \mathrm{z}=-2.312$, $\mathrm{p}<0.05)$,

- Your organization uses personality tests to select employees $(U=17800, z=-2.111$, $\mathrm{p}<0.05)$. 
Table 5. Testing the differences between respondents employed in production and service organizations in the representation of human resource selection process activities, using the Mann-Whitney test

\begin{tabular}{|l|c|c|c|}
\cline { 2 - 4 } \multicolumn{1}{c|}{} & \multicolumn{3}{c|}{ Mann-Whitney } \\
\cline { 2 - 4 } \multicolumn{1}{c|}{} & $\mathrm{U}$ & $\mathrm{Z}$ & $\mathrm{p}$ \\
\hline Your organization uses knowledge tests to select employees & 1662.500 & -2.312 & $.021^{*}$ \\
\hline Your organization uses personality tests to select employees & 1780.000 & -2.111 & $.035^{*}$ \\
\hline
\end{tabular}

Grouping variable:type of activity

Meaning:

* $\quad$ Significance at a level less than 0,05

** Significance at a level less than 0,01

Pearson's $\chi^{2}$ test determined the differences between respondents employed in production and service organizations in naming the person interviewing with candidates $(\chi 2=13,526, p<0.01)$, in production organizations it is done by the director of human resources, and in service teams it is done by the experts. Pearson's $\chi 2$ test did not identify differences between respondents employed in manufacturing and service organizations in stating who makes the final decision on hiring workers and who creates job advertisements in the organization.

The following results were obtained by analysing the representation of the activities of the sub-process of orientation and introduction to work in relation to the activities of the organization:

a) In relation to the activity of the organization, the Mann-Whitney test found that the answers of respondents employed in service organizations do not differ from the answers of respondents employed in production organizations, but Pearson's $\chi 2$ test found differences between respondents employed in production and service organizations regarding the person who is assigned to be a mentor to trainees $\left(\chi^{2}=9,960, \mathrm{p}\right.$ $<0.041)$ - in production organizations the mentor is a fellow associate, while in service organizations it is trainees' direct superior.

Table 6. Cross-tabulation with a presentation of the distribution of the answers to the representation of the activities of the process of orientation and introduction to work, depending on the type of activity of the organization in which the respondent is employed

\begin{tabular}{|l|c|c|c|c|}
\hline \multirow{2}{*}{$\begin{array}{l}\text { The person who is assigned to be a } \\
\text { mentor to trainees }\end{array}$} & \multicolumn{3}{|c|}{ Pype of activities } \\
\cline { 2 - 5 } & Count & Column N \% & Count & Column N \% \\
\cline { 2 - 5 } & 13 & $22.8 \%$ & 32 & $49.2 \%$ \\
\hline Direct superior & 4 & $7.0 \%$ & 3 & $4.6 \%$ \\
\hline Superiors and colleagues & 25 & $43.9 \%$ & 19 & $29.2 \%$ \\
\hline Fellow associate & 12 & $21.1 \%$ & 7 & $10.8 \%$ \\
\hline It is determined arbitrarily & 3 & $5.3 \%$ & 4 & $6.2 \%$ \\
\hline There is no mentor to do the internship & \multicolumn{2}{|c}{ Service } \\
\hline
\end{tabular}

The following results were obtained by analysing the representation of the activities of the sub-process of performance evaluation and rewarding employees in relation to the activities of the organization:

a) In relation to the activities of the organization Mann-Whitney test found that respondents employed in service organizations with a higher score and degree of agreement rated the following activities than respondents employed in production organizations:

- In the organization in which you are employed there is a person in charge of controlling your work $(U=1506,500, z=-2,398, p<0.05)$ 
- After evaluating your results, you receive feedback on whether or not you met the set goals $(\mathrm{U}=1444.500, \mathrm{z}=-2.764, \mathrm{p}<0.01)$

- Your work evaluates compliance with procedures and rules $(U=1658.000, z=-1.920$, $\mathrm{p}=0.05)$

- In your organization, the success of the work is measured by submitting periodic reports of employees $(\mathrm{U}=1262,000, \mathrm{z}=-4,364, \mathrm{p}<0.01)$,

- Rewarding is applied through attending courses / seminars $(\mathrm{U}=1756.500, \mathrm{z}=-2.117$, $\mathrm{p}<0.05)$,

- Improvement in your organization depends on the personal connections $(U=1617.000$, $\mathrm{z}=-2.835, \mathrm{p}<0.01$ ),

- Rewarding is applied through the possibility of choosing work tasks $(\mathrm{U}=1856.000$, $\mathrm{z}=-2.083, \mathrm{p}<0.05)$,

- Rewarding is applied through promotion $(U=1568.500, z=-2.620, p<0.01)$,

- Rewarding is applied through written acknowledgments $(\mathrm{U}=1711.000, \mathrm{z}=-3.009, \mathrm{p}$ $<0.01)$,

while the respondents who are employed in production organizations rate the following activities with a higher grade and the degree of agreement than the respondents employed in service organizations:

- Estimation of your results in work affects earnings ( $U=1337,500, z=-1,997, p<0.05)$,

- Your organization has an appropriate performance appraisal system $(U=1337.500$, $\mathrm{z}=-3.101, \mathrm{p}<0.01)$

- There is an appropriate reward system in your organization $(U=1412,000, z=-2,959$, $\mathrm{p}<0.01$ ),

- Accuracy is evaluated in your work $(\mathrm{U}=1642.500, \mathrm{z}=-2.188, \mathrm{p}<0.05)$,

- Your work evaluates compliance with deadlines ( $U=1612.500, z=-2.191, p<0.05)$,

- In your organization, the success of the work is measured by comparing the set and achieved goals in a given period $(\mathrm{U}=1671,500, \mathrm{z}=-1,996, \mathrm{p}<0.05)$,

- Rewarding is applied through monthly incentives $(U=1387.500, z=-3.468, p<0.01)$.

Table 7. Testing the differences between respondents employed in production and service organizations in relation to the representation of the activities of the process of performance evaluation and rewarding using the Mann-Whitney test

\begin{tabular}{|c|c|c|c|}
\hline & \multicolumn{3}{|c|}{ Mann-Whitney } \\
\hline & $\mathrm{U}$ & Z & $\mathrm{p}$ \\
\hline $\begin{array}{l}\text { In the organization you are employed in, there is a person who is in } \\
\text { charge of controlling your work }\end{array}$ & 1506.500 & -2.398 & $.016^{*}$ \\
\hline $\begin{array}{l}\text { After evaluating your results, you receive feedback on whether or not } \\
\text { you have met the set goals }\end{array}$ & 1444.500 & -2.764 & $.006^{* *}$ \\
\hline Evaluating your work results affects earnings & 1551.000 & -1.997 & $.046^{*}$ \\
\hline $\begin{array}{l}\text { There is an appropriate performance appraisal system in your } \\
\text { organization }\end{array}$ & 1337.500 & -3.101 & $.002 * *$ \\
\hline There is an appropriate reward system in your organization & 1412.000 & -2.959 & $.003 * *$ \\
\hline Accuracy is evaluated in your work & 1642.500 & -2.188 & $.029 *$ \\
\hline Your work evaluates compliance with procedures and rules & 1658.000 & -1.920 & $.055^{*}$ \\
\hline Compliance with deadlines is assessed in your work & 1612.500 & -2.191 & $.028^{*}$ \\
\hline $\begin{array}{l}\text { In your organization, job performance is measured by submitting } \\
\text { periodic employee reports }\end{array}$ & 1262.000 & -4.364 & $.000 * *$ \\
\hline $\begin{array}{l}\text { In your organization, the success of doing business is measured by } \\
\text { comparing set and achieved goals in a given period }\end{array}$ & 1671.500 & -1.996 & $.046^{*}$ \\
\hline
\end{tabular}




\begin{tabular}{|l|c|c|c|}
\hline Rewarding is applied through monthly incentives & 1387.500 & -3.468 & $.001^{* *}$ \\
\hline Rewarding is applied through attending courses / seminars, & 1756.500 & -2.117 & $.034^{*}$ \\
\hline Rewarding is applied through the possibility of choosing work tasks & 1856.000 & -2.083 & $.037^{* *}$ \\
\hline Rewarding is applied through promotion & 1568.500 & -2.620 & $.009^{*}$ \\
\hline Rewarding is applied through written acknowledgments & 1711.000 & -3.009 & $.003^{*}$ \\
\hline Advancement in your organization depends on the connection & 1617.000 & -2.835 & $.005^{*}$ \\
\hline
\end{tabular}

Grouping variable:type of activity

Meaning:

* $\quad$ Significance at a level less than 0,05

** Significance at a level less than 0,01

The following results were obtained by analysing the representation of the activities of the sub-process of job satisfaction and motivation in relation to the activities of the organization:

a) In relation to the activities of the organization Mann-Whitney test found that respondents employed in service organizations rated the following activities with a higher score and degree of agreement than respondents employed in manufacturing organizations:

- You think you would do a better job if interpersonal relationships were better $(\mathrm{U}=1586.500, \mathrm{z}=-2.327, \mathrm{p}<0.05)$

- Too much administration makes your work difficult for you ( $U=1366.000, z=-2.978$, $\mathrm{p}<0.01)$

Table 8. Testing the differences between respondents employed in production and service organizations in relation to the represented activities of the process of job satisfaction and employee motivation using the Mann-Whitney test

\begin{tabular}{|l|c|c|c|}
\cline { 2 - 4 } \multicolumn{1}{c|}{} & \multicolumn{3}{c|}{ Mann-Whitney } \\
\cline { 2 - 4 } \multicolumn{1}{c|}{} & $\mathrm{U}$ & \multicolumn{2}{c|}{$\mathrm{Z}$} \\
\hline $\begin{array}{l}\text { Too much administration makes your work difficult for you } \\
\text { You think you would do a better job if interpersonal relationships } \\
\text { were better }\end{array}$ & 1366.000 & -2.978 & $.003 * *$ \\
\hline
\end{tabular}

Grouping variable:type of activity

Meaning:

* $\quad$ Significance at a level less than 0,05

** Significance at a level less than 0,01

The following results were obtained by analysing the representation of the activities of the sub-process of human resources development, in relation to the activities of the organization:

a) In relation to the activity of the organization, the Mann-Whitney test established that the respondents employed in service organizations rated the following activities with a higher grade and higher degree of agreement than the respondents employed in production organizations:

- Your organization organizes training and development for employees ( $U=1357.000$, $\mathrm{z}=-2.994, \mathrm{p}<0.01)$

- During training and specialization, the organization offers opportunities: Payment of education costs $(U=1562.500, z=-2.575, p<0.01)$,

- During training and specialization, the organization offers opportunities: Part-time work $(\mathrm{U}=1743.000, \mathrm{z}=-2.378, \mathrm{p}<0.05)$,

- You feel that additional training would improve your efficiency in the work you do $(\mathrm{U}=1481.000, \mathrm{z}=-2.453, \mathrm{p}<0.05)$,

- There is a budget in your organization for training and education of employees $(\mathrm{U}=1325.000, \mathrm{z}=-3.146, \mathrm{p}<0.01)$. 
Table 9. Testing the differences between respondents employed in production and service organizations in relation to the represented activities of the human resources development process, using the Mann-Whitney test

\begin{tabular}{|l|c|c|c|}
\cline { 2 - 3 } \multicolumn{1}{l|}{} & \multicolumn{2}{c|}{ Mann-Whitney } \\
\cline { 2 - 4 } \multicolumn{1}{l|}{$\begin{array}{l}\text { Your organization organizes training and development for } \\
\text { employees }\end{array}$} & 1357.000 & -2.994 & $.003^{* *}$ \\
\hline $\begin{array}{l}\text { You feel that additional training would improve your efficiency in } \\
\text { the work you do }\end{array}$ & 1481.000 & -2.453 & $.014^{* *}$ \\
\hline $\begin{array}{l}\text { There is a budget in your organization for training and educating } \\
\text { workers }\end{array}$ & 1325.000 & -3.146 & $.002^{* *}$ \\
\hline Have you had training in the last period & 1289.000 & -3.610 & $.000^{* *}$ \\
\hline $\begin{array}{l}\text { During training and specialization, the organization offers } \\
\text { opportunities: Part-time work }\end{array}$ & 1743.000 & -2.378 & $.017^{*}$ \\
\hline $\begin{array}{l}\text { During training and specialization, the organization offers } \\
\text { opportunities: Payment of education costs }\end{array}$ & 1562.500 & -2.575 & $.010^{* *}$ \\
\hline
\end{tabular}

Grouping variable:type of activity

Meaning:

* $\quad$ Significance at a level less than 0,05

** $\quad$ Significance at a level less than 0,01

The respondents employed in production organizations rated the following activities with a higher grade and higher degree of agreement than the respondents employed in service organizations:

- During training and specialization, the organization offers opportunities: Payment of education costs $(U=1562.500, z=-2.575, p<0.01)$,

- During training and development, the organization offers opportunities: Part-time work $(\mathrm{U}=1743.000, \mathrm{z}=-2.378, \mathrm{p}<0.05)$.

- The Mann-Whitney test indicated that respondents employed in production organizations had more training time $(\mathrm{U}=1289.000, \mathrm{z}=-3.610, \mathrm{p}<0.01)$.

\section{4, RESULTS-RELATED DISCUSSION}

The analysis of the differences between service and production organizations in the application of the activities of the human resources management process has established that:

1. Within the process of job analysis in service organizations, statistically significant differences showed that employees were more often able to discuss their job descriptions with their superiors, and that job systematization was done by the human resources department, while in production organizations the systematization was done by the legal department. The possibility of discussion of a job description indicates a less formal process of job analysis in service organizations that allows employees to clarify any possible ambiguities related to business goals, defined criteria and to indicate possible inconsistencies between job description and what is really done, in such a way that enables continuous updating of the job description as a basic document in the upcoming human resources management sub-processes. The difference in the responsibility for job systematization in service organizations left to the human resources department indicates a positive step that organizations have taken in managing their human resources by forming a department whose main job is to define activities and processes of employee management as opposed to production organizations, which still leave it to the legal department, which deals exclusively with administrative matters related to employees. 
2. Within the process of human resources planning in service organizations, statistically significant differences showed that there is continuous monitoring of employee retirement for a period of 5 years and that there is a systematization of jobs, which indicates that service organizations plan long-term employee movements, which enables them a solid starting point for defining a specific human resources plan or strategy that will be implemented in the coming period. The only thing that needs to be taken into account is that the defined human resources plan is harmonized with the strategic goals of the organization.

3. Within the process of recruiting human resources in service organizations, statistically significant differences showed that when there is a need for a new job, potential candidates are hired primarily by selecting people from outside the organization and that if applicants do not meet the requirements of the competition, the organization informs them that they have been rejected. The selection of people outside the organization indicates a low utilization of internal sources of recruitment as well as their advantages in motivating employees, reducing the cost of external recruitment, the cost of ,vacancies” and creating a clear system of employee promotion. Only when the organization has exhausted the possibilities of internal recruitment of candidates should it apply the sources of external recruitment. The answer to the rejected candidates provides the opportunity to create a good image of the organization in the market, because one of the biggest objections of the rejected candidates is getting feedback on the reasons for non-compliance with a particular job. Also, organizations are given the opportunity to gain insight into the ranking of the desirability of their organization in the environment and in relation to the competition, based on monitoring the qualifications of candidates.

4. Within the process of human resources selection, statistically significant differences showed that in service organizations, knowledge tests and personality tests are used when selecting employees, while a team of experts is in charge of interviewing candidates. These tests as a chosen method of selection indicate the specificity of the service sector in which the personality of employees is crucial in jobs that involve direct contact with clients, and who are in charge of assessing the quality of service provided. As the team of experts is in charge of the selection process, it can be concluded that the criteria of the selection process are defined at three levels (organization, function and job), which allows a higher degree of fit of the candidate with job description and job requirements as well as a greater probability of selecting the needed candidate and not the available one.

5. Within the process of orientation and induction in service organizations, statistically significant differences showed that the person in charge of the training of trainees in service organizations is their direct superior, while in production organizations it is a colleague who is also an associate, which indicates the specificity of employees in the service sector, who, due to the intangibility of their services, need to be involved in the entire service process in the organization. Cooperation with the immediate superior enables new employees to get all the necessary information about their job, its connection with other jobs, goals and tasks, etc.

6. Within the process of performance evaluation and remuneration in service organizations, statistically significant differences showed that there is a person in charge of controlling the work of each employee, that employees receive feedback after evaluating the results of work on whether or not they met the set goals, that their work is evaluated by whether they are following procedures and rules, that the success of work is measured by submitting periodic reports of employees, that rewards are applied through attending courses/seminars, but also that work promotion depends on personal connections, that 
rewards are applied through the possibility of choosing work tasks, through promotion and written acknowledgments. All activities singled out by the respondents in service organizations indicate that the system of rewards is not well defined, because it is expected that the system would be assessed as appropriate if the results would affect earnings as a basic material reward, if parameters such as deadlines, accuracy, timeliness, etc. would be assessed, if that success is measured by comparing set and achieved goals, if there are monthly incentives, etc. Insufficiently well-defined reward system affects motivation and job satisfaction as well as interpersonal relationships, which in the service sector, that is in direct contact with customers, primarily affects the quality of service and customer satisfaction and also results in poor performance of the organization.

7. Within the process of motivation and job satisfaction in service organizations, statistically significant differences showed that employees in service organizations would do a better job if interpersonal relationships were better and that their work was made more difficult by too much administration. Poor interpersonal relationships negatively affect all aspects of business, especially in service organizations. Sources of employee dissatisfaction can be numerous and the basic task of the human resources department is to determine the sources of dissatisfaction and define ways to overcome them. Too much administration in service organizations primarily affects the flexibility and speed of providing service to customers. The possibility of creating databases and computerization of business greatly facilitates the management of administration that is necessary for doing business in any organization.

8. Within the process of development and training of human resources in service organizations, statistically significant differences have shown that in service organizations training and development of employees are organized more often, that during training and development the organizations offer opportunities: payment of education costs and parttime work, also, that there is a budget in the organizations that is intended for training and education of workers, and that employees believe that additional training improves their efficiency in the work they do. The obtained results are certainly encouraging because they primarily indicate that service organizations plan the budget for employee development and training in advance, that they apply methods of stimulating employees in the training process and that employees view additional education as a tool that enables them to do their jobs better. What should be taken into account is that the goals of development and training of employees are in line with the strategic goals of the organization, that the choice of educational methods is aligned with the capabilities of the organization, that training is available to employees at all levels to provide equal opportunities and avoid bad interpersonal relations as well as to connect additional training and education with the system of rewarding employees. The development and training process is recognised as the key driver for gaining competitive advantage (Armstrong, M., Baron, A., 2005). Insight in this important process in service organizations in Rasina district was a subject of research (Tot, V., Savić Tot., T., Aleksić, S., 2019) and the results indicated the most important characteristics that can be implemented in service organizations.

\section{5, CONCLUSION}

The hypothesis set in the paper was confirmed because as shown in the research results in each sub-process of the Human Resource Management process there is a statistically significant difference related to human resource management activities in service organizations versus production organizations. 
Considering the specifics of the service process itself, which is based on a much closer relationship with customers, creating a service in front of the customer, more realistic and larger turnover, it was to be expected that human resource management activities of service organizations in some segments are much more developed than in the manufacturing sector. It is as if the role and place of Human Resource Management is better defined and more purposeful, because employees are realistically a key resource of service organizations. Instead of a conclusion, we give an overview of the significant results of each sub-process of Human Resource Management as well as a recommendation due to the new situation.

In the analysis of the work, the systematization was done in closer cooperation between superiors and executors, and that work was done by the human resources department. However, today's business requires redefining jobs in the service sector, observing them through the prism of the application of information technology, in order to adapt to the impact and consequences of the pandemic. Only human resource planning in service organizations marks continuous monitoring of employee retirement as well as long-term human resource planning, but today we have a redefining of strategic goals and the planning must be aligned with them. The results of the research indicate the need to change the focus on internal resources in the recruitment sub-process.

The selection of human resources is well organized, and it should include the verification of new knowledge that is a consequence of the pandemic and the changed systematization of jobs.

Introduction of employees to work (induction) as the result of the research, showed the role of the superior in the service organizations, and our recommendation is to raise it to a higher level, i.e., to mentoring in the sub-process of induction and to connect it with building a system of remuneration and evaluation performance, which, among other things, means that both mentors and new employees have benefits, as well as sanctions.

The reward system, especially nowadays, must be transparent, because the service sector is facing serious business cuts. Unfortunately, the activities singled out as significant by the respondents in service organizations indicate an insufficiently well-defined reward system, because it would be expected that the system would be assessed at least as appropriate, that the results would affect earnings as a basic material reward, and parameters such as deadlines, accuracy, timeliness, etc., also that success is measured by comparing set and achieved goals, that there are monthly incentives, etc. Insufficiently well-defined reward system affects motivation and job satisfaction, as well as interpersonal relationships, which in the service sector, that is in direct contact with customers, primarily affects the quality of service and customer satisfaction and results in poor performance of the organization.

According to the respondents, the motivation and satisfaction of employees in service organizations today are burdened with too much administration and bad interpersonal relations, which will only be more pronounced with the crisis, and therefore the administration process should be automated and digitized as much as possible, while at the same time it should be worked on the cohesion of employees as much as possible, as well as on creating clear goals necessary for the functioning of the organization itself.

The process of employee development and training must be in line with the acquisition of the necessary knowledge and skills, caused by the two key factors of today's pandemic business and the digitalization of the entire business. 


\section{REFERENCES}

Amble, B., (2006): Organizations Slow To Integrate New Hires, accessed on $4^{\text {th }}$ July 2014, http://www.management-issues.com/2006/12/15/research/organisations-slow-to-integrate-new-hires.asp

Anderson, N., Shackleton, V., (1993): Successful Selection Interviewing, Blackwell, Oxford

Anthony, W. P., Kacmar, K. M., Perrewe, P. L., (2002): Human Resource Management: A Strategic Approach, 4th ed., New York: South-Western

Armstrong, M., (2008): Strategic Human Resource Management-A Guide to Action, 4 ed., Kogan Page Limited, London

Armstrong, M., Baron, A., (2005): Managing Performance: Performance Management In Action, London: Cipd

Bahtijarević Šiber, F., (1999): Menadžment ljudskih potencijala, Golden marketing, Zagreb)

Baird, L., Meshoulam, I., (1988): Managing Two Fits Of Strategic Human Resource Management, Academy of Management Review, 13(1): pp. 116-128

Bartel, A. P., (1994): Productivity Gains from the Implements of Employee Training Programs, Industrial Relations 33(4), pp 411-425

Bartel, A. P., (2004): Human Resource Management and Organizational Performance: Evidence From Retail Banking, Industrial and Labour Relations Review, (57): pp181-204

Bennison, M., Casson J., (1984): The manpower planning handbook, McGraw Hill Higher Education

Billsberry, J., (2007): Experiencing recruitment and selection, Hoboken, NJ: Wiley \& Sons

Black, S. E., Lynch, L., (2001): How to compete: The impact of workplace practices and information technology on productivity, Review of Economics and Statistics, no. 83., pp. 434-445

Bloisi, W., (2003): Management and organizational behaviour, Mc Graw-Hill companies

Bogićević Milkić, B., (2006): Menadžment ljudskih resursa, Centar za izdavačku delatnost Ekonomskog fakulteta: Čugura Print, Beograd

Bowin, R. B., Harvey, D., (2001): Human Resource Management: An Experiential Approach. Englewood Cliffs, NJ: Prentice Hall

Bramham, J., (1994): Human Resource Planning (2ndEds), London, IPD

Breaugh, J. A., Macan, T. H., Grambow, D. M., (2008): Employee recruitment: Current knowledge and directions for future research, according to Hodgkinson, G. P., Ford, K. J., International Review of Industrial and Organizational Psychology, no. 23., (pp. 45-82), New York: John Wiley \& Sons

Brown, S. P., (1996): A meta-analysis and review of organizational research on job involvement, Psychological Bulletin, no. 120., pp. 235-255

Carr, G., (2005): Investigating the motivation of retail managers at a retail organization in the Western Cape, Unpublished mini-thesis, University of the Western Cape, South Africa

Cascio, F. W., (1998): Applied psychology in human resource management, Prentice - Hall, London

Cornelius, E., Carron, T., Collins, M., (1979): Job Analysis Models and Job Classifications, Personnel Psychology, no. 22., pp. $693-708$

DeCenzo A. D., Robbins P.S., Verhulst L. S., (2010): Fundamental of Human Resource Management, 11th ed., Wiley and Sons

Delaney, J. T., Huselid, M. A., (1996): The Impact Of Human Resource Management Practices On Perceptions Of Organizational Performance, Academy of Management Journal, 39(4) pp. 949-969 
Delery, J.E., (1998): Issues Of Fit In Strategic Human Resource Management: Implications For Research, Human Resource Management Review, no. 8., pp.289-310

DeNisi, A. S., Griffin, R. W., (2008): Managing Human Resources (3rd Ed) Boston: Houghton-Mifflin

Dessler, G., (2002): Framework of Human Resource Management, 2nd Edition, The Dryden Press, Prentice Hall, New Jersey

Devadoss, P., Pan, S., (2007): Enterprise Systems Use: Towards a Structurational Analysis of Enterprise Systems Induced Organizational Transformation, Communications of the Association for Information Systems, no. 19., pp. 352-385

Dulebohn, H. J., Ferris, R. G., Stood, T. J., (1995): Handbook of human resource management, Blackwell Oxford, UK, pp. 18-41

Foot, M., Hook C., (2011): Introducing Human Resource Management, Financial Times/ Prentice Hall; 6 ed

French, J. R. P. Jr, Rodgers, W. R., Cobb, S., (1994): Adjustment as person-environment fit In Coping and Adaptation, Basic Books, New York, pp. 316-333

Ganser, T., (2000): Evaluating a University Mentoring Program for K-12 Teachers: The University of Wisconsin-Whitewater Beginning Teacher Assistance Program

Gerhart, B., Trevor, C. O., (1996): Employment Variability under Different Managerial Compensations Systems, Academy of Management Journal, 39(6), pp. 1692-1712

Gómez-Mejía, L. R. (1992): Structure and Process of Diversification, Compensation Strategy, and Firm Performance Strategic Management Journal, 13(5) pp. 381-397

Gregg, P., Wadsworth J., (1999): The State of Working Britain, Manchester University Press, Manchester

Grubić - Nešić, L., (2005): Razvoj ljudskih resursa, Novi Sad, AB print

Hansson, B., (2001): Essays on Human Capital Investments, Stockholm University, Stockholm

Huselid, M. A., (1995): The impact of Human Resource Management Practices on Turnover, Productivity and Corporate Financial Performance, Academy of Management Journal, pp.635-672

Huselid, M. A., Becker, B. E., Beatty, R. W., (2005): The Workforce Scorecard - Managing Human Capital to Execute Strategy, Harvard Business School Press, Boston, MA

Ichiniowski, C., Shaw, K., Prennushi, G., (1997): The effects of human resource management practices on productivity: A study of steel finishing lines, The American Economic Review, no. 87., pp. 291-313

Jackson, S.E., Schuler, R.S., (1995): Understanding human resource management in the context of organizations and their environments, Annual Review of Psychology, no. 46, pp. 237264

Katz, R. L., (1974): Skills of an effective administrator, Harvard Business Review, 52(5), pp. 90-120

Kepes, S., Delery, J. E., (2007): HRM systems and the problem of internal fit, according to: P. C., Boxall, J. Purcelland, P. M. Wright (Eds.), The Oxford handbook of human resource management, pp. 385-404

Klein, H. J., Weaver, N. A., (2000): The effectiveness of an organizational-level orientation training program in the socialization of new hires, Personnel Psychology, 53 (1), pp. 47-66

Koch, J. M., McGrath, J. M., (1996): Improving Labour Productivity: Human Resource Policies Do Matter, Strategic Management Journal, 17(5) pp. 335-354

Levine, E. L., Ash, R. A., Hall, M., Sistrunk, F., (1983): Evaluation of Job Analysis Methods by Experienced Job Analyst, Academy of Management Journal, no. 26, pp. 339-348

Lewis, C., (1985): Employee Selection, London: Hutchinson 
Locke, E. A., (1976): The Nature and Causes of Job Satisfaction, according to: Dunnette M. D., (Ed.), Handbook of Industrial and Organizational Psychology, pp. 1297-1343. Chicago: Rand McNally

McCormic, E. J., (1979): Job Analysis: Methods and Applications, New York: AMACOM

McDonald, D., Smith A., (1995): A Proven Connection: Performance Management and Business Results, Compensation and Benefits Review, 27(1), pp. 59-64

Mendonca, M., Kanungo, N. R., (1996): Impact of culture on performance management in developing countries, International Journal of Manpower

Miles, R. E., Snow, C. C., (1984): Fit, Failure and The Hall of Fame, California Management Review, 26(3), pp. 10-28

Miller, F. B., Coghill, M. A., (1964): Sex and the Personnel Manager, Industrial and Labor Relations Review, no. 18., pp. 32-44

Mondy, R. W., Noe, R. M., Premeaux, S. R., (2002): Human Resources Management (8Ed.), Upper Saddle River, New Jersey: Pearson Education, Inc.

Mullins, J. L., (2007): Management and organizational behaviour, Seventh Edition, Pearson Education Limited, Essex, pp. 700

Naisby, A., (2002): Appraisal and Performance Management, Spiro Press, London

Noe, R. A., Hollenbeck, J., Gerhart, B., Wright, P., (2005): Menadžment ljudskih potencijala, Mate, Zagreb

Noe, R., Hollenbeck, J., Gerhart, B., Wright, P., (2005): Menadžment ljudskih potencijala, Mate, Zagreb

Patterson, M., West, M., Lawtthorn, R., Nickell, S., (1997): Impact of people management practices on business performance, London: Institute of Personnel and Development

Pulakos, D. E., (2009): Performance management: A new approach for driving business results, A John Wiley and Sons, 1td., Publications

Purcell, J., Kinne, N., Hutchinson, S., (2003): Understanding the people and performance link: unlocking the black box, London: CIPD, pp.88

Savić Tot, T., (2016): Razvoj modela strategijskog menadžmenta ljudskih resursa u funkciji sticanja konkurentske prednosti, Doktorska disertacija, Fakultet tehničkih nauka, Univerzitet Novi Sad

Schuler, R. S., (1995): Managing Human Resources, $5^{\text {th }}$ ed, West Publishing Company

Schuler, R. S., Jackson, S., (1999): Linking Competitive Strategies with Human Resource Management Practices, according to: Strategic human resource management, Schuler R. S., and Jackson, S., Oxford: Blackwell Publishers Ltd., pp. 159-76

Sherman, A., Bohlander, G., Snell, S., (1998): Managing Human Resources, 11th edn., Cincinnati, OH: South Western College Publishing

Shih, H. A., Chiang, Y. H., Hsu, C. C., (2006): Can high performance work systems really lead to better performance? International Journal of Manpower, 27(4), pp. 741-763

Siddique, C. M., (2004): Job analysis: A strategic human resource management practice, International journal of Human Resource Management, 15(1), pp. 219-244

Swanson, R. A., Holton, E. F., (2001): Foundations of Human Resource Development, San Francisco: Berrett-Koehler

Tamkin, P., Hillage, J., Cummings, J., Bates, P., Barber, L., Tackey, N., (2000): Doing Business Better: The Long Term Impact of Investors in People, FOCUS central London

Thomason, G., (1988): A Textbook of Human Resource Management London: Institute of Personnel Management

Torrington, D., Hall, L., Taylor, S., (2004): Menadžment ljudskih resursa, Data status, Beograd 
Tot, V., Savić Tot., T., Aleksić, S., (2019): Human resources department role in employees training and education in service sector, 4th International Thematic Monograph Modern Management Tools and Economy of Tourism Sector in Present Era, Association of Economists and Managers of the Balkans in cooperation with the Faculty of Tourism and Hospitality, Ohrid, Macedonia, Belgrade, ISBN 978-86-80194-29-5, pp. 413 - 440, https:// doi.org/10.31410/tmt.2019.413,

Uchitelle, L., Kleinfeld, N., (1996): The Downsizing of America, New York Times

Vujić, V., Ćamilović, S., (2007): Osnove menadžmenta ljudskih resursa, Tekon-tehnokonsalting, Beograd

Ward, P. T., Leong, G. K., Boyer, K. K., (1994): Manufacturing Proactiveness and Performance, Decision Sciences, 25(3), pp. 337-357

Werner, M., Randy L. D., (2009): Human resource development, 6th ed., Cengage Learning

Wright, P. M., Snell, S. A., (1991): Toward an Integrative View of Strategic Human Resource Management, Human Resource Management Review, 1(3), pp. 203-225

Wright, P. M., McMahan, G. C., (1992): Theoretical perspectives for strategic human resource management, Journal of Management, 18 (2) pp. 295

Wright, P. M., McMahan, G. C., (1999): Theoretical Perspectives for SHRM, according to: In Strategic Human Resource Management, (Eds.) R. Schuler and S. Jackson, pp. 49-72. Oxford: Blackwell Publishers Ltd.

Wright, P. M., McMahan, G. C., Snell, S. A., Gerhart, B., (2001): Comparing Line and HR Executives-Perceptions of HR Effectiveness: Services, Roles, and Contributions, Human Resource Management, no. 30, pp. 111-123 